\title{
BONEBRIDGE - ACTIVE BONE CONDUCTION HEARING AID
}

\author{
MADALINA GEORGESCU ${ }^{1,2}$, V. BUDU ${ }^{1,2}$, DANIELA VRINCEANU ${ }^{3}$, MAGDALENA CERNEA $^{1}$ \\ ${ }^{1}$ Audiology, ENT - „Carol Davila” University of Medicine and Pharmacy, Bucharest, ROMANIA, ${ }^{2}$ Audiology, ENT - \\ Institute of Phono-Audiology and ENT Functional Surgery, Bucharest, Romania, ${ }^{3}$ ENT Department, University \\ Emergency Hospital Bucharest, Romania \\ E-mail: madalina.georgescu@otomed-center.ro
}

\begin{abstract}
For individuals with conductive or mixed hearing loss, a bone conduction system can be a very effective treatment option. These systems bypass the outer and middle ear to send sound vibrations directly to the cochlea. This offers a natural sound quality for recipients. BONEBRIDGE is the first active, intact skin hearing implant for bone conduction stimulation, ideal for moderate to severe conduction hearing losses. It is a semi-implantable system, consisting of a surgical implantable part and an externally worn audio processor. Biomaterials used proved their safety, with very low rate of medical complications (skin infections, chronic suppurative otitis media, biofilm formation or extrusion).
\end{abstract}

Keywords: conductive hearing loss, active bone conduction, semi-implantable hearing aid, biomaterials

\section{INTRODUCTION}

360 million persons (5\% of world population) live with disabling hearing loss. From this huge hearing-impaired population, 32 million are children [1].

Bilateral hearing loss urges for treatment, due to its many consequences, not only medical, but behavioral and social as well. Its severity is even more prominent in congenital or prelingually cases, in whom lack of normal hearing leads to poor speech and language development.

Depending on the site of lesion, three major categories of hearing loss are described (Figure 1):

- Conductive hearing loss (Figure 2), with lesions in the outer or/and middle ear - in these cases, sounds coming through air conduction (AC) are delayed by the lesion in the transmission pathway, but sounds coming through bone conduction (BC) are normally transmitted to the inner ear. In Pure Tone Audiometry (PTA) a gap is present between the two types of sound transmission, with BC threshold (THR) in normal range between o and $20 \mathrm{~dB}$;

- Sensorineural hearing loss, with lesion located in the inner ear or auditory nerve;

- Mixt hearing loss, with combined lesions of the previously two types of hearing loss.

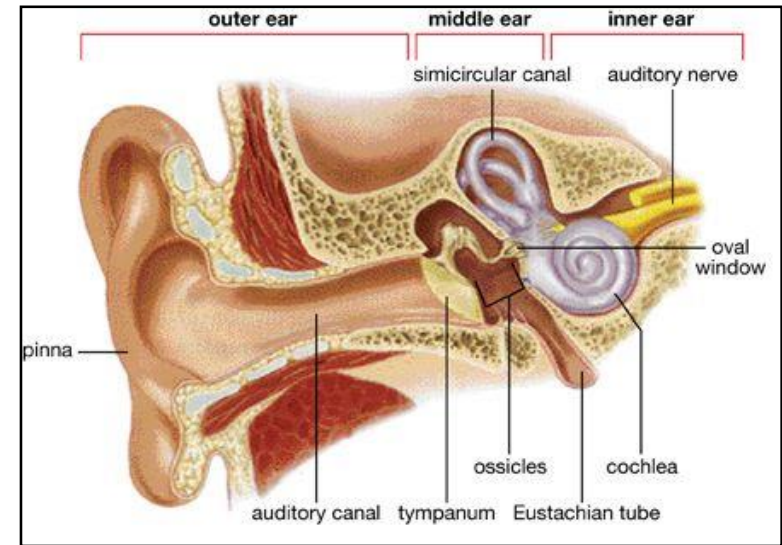

Figure 1. Type of hearing loss and lesion site

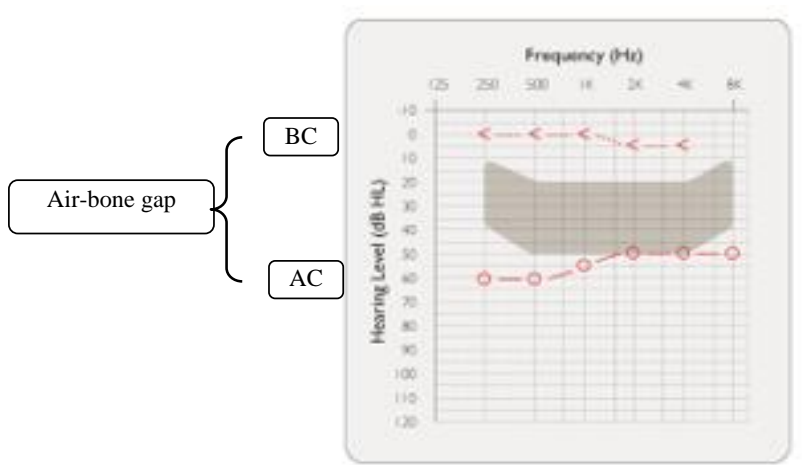

Figure 2. Conductive hearing loss: gap between air and bone conduction THR in PTA; normal THR in BC

\section{METHOD}

Conductive hearing losses benefit in many cases from medical or surgical treatment, with restoration of the functionality of the eardrum and ossicular chain and restoration of normal hearing as well.

There are still some cases where conductive or mixed hearing losses are permanent and the only way to provide a normal hearing is by amplification with a hearing aid, conventional (Figure 3) or implantable (Figure 4). BONEBRIDGE is a semi-implantable bone conduction hearing implant recommended in patient over 5 years of age with permanent conductive or mixed hearing loss [2], [3]. 


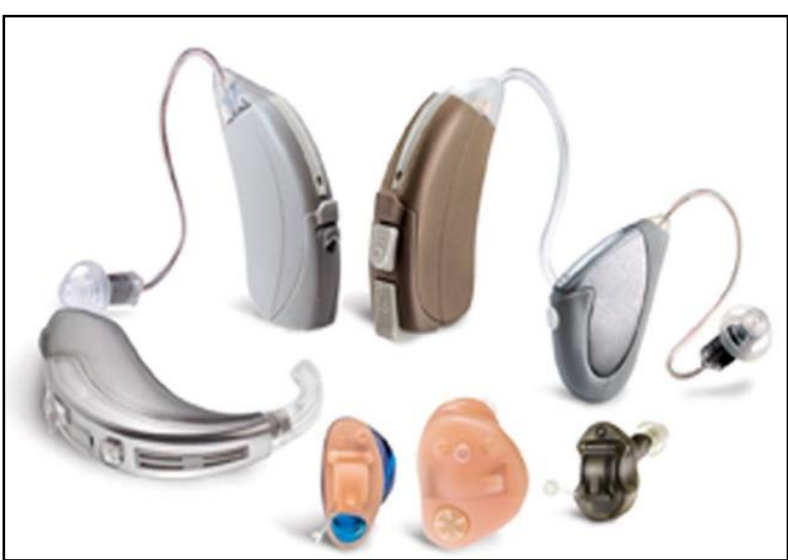

Figure 3. Conventional hearing aid (different types)

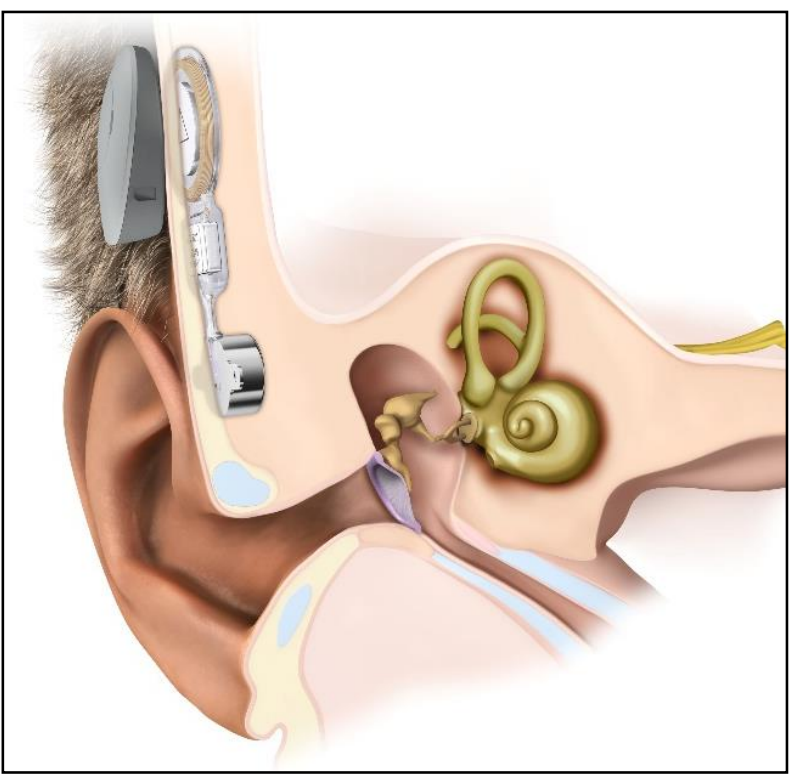

Figure 4. Implantable bone conduction hearing aid (ex. BONEBRIDGE)

From audiological point of view, there are certain criteria to be fulfilled (Figure 5) [4], [5]:

- Conductive component of the hearing loss with bone conduction threshold better than $45 \mathrm{~dB}$ (Figure 5a);

- $\quad$ Single sided deafness (Figure 5b).

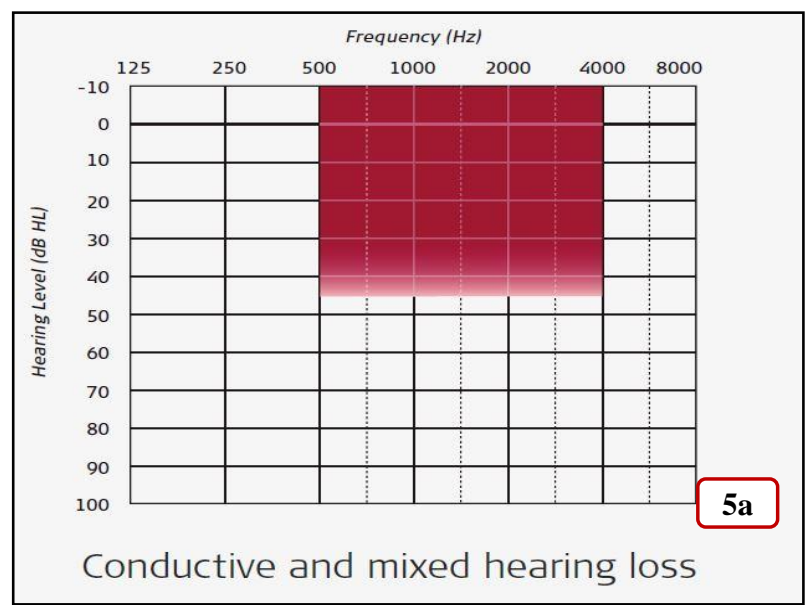

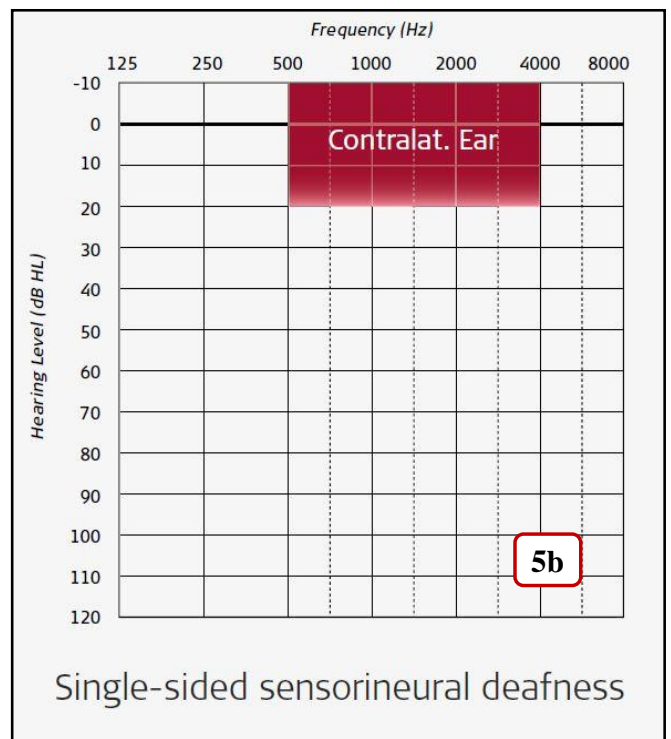

Figure 5. Audiological criteria for BONEBRIDGE hearing implant: 5a) - conductive/mixed hearing loss: shadow area is the interval of the accepted $\mathrm{BC}$ hearing thresholds in PTA; 5b) - sigle sided deafness: shadow area is the interval of the accepted $\mathrm{BC}$ hearing thresholds in PTA of the normal hearing ear.

\section{RESULTS}

Implantable hearing aids must achieve two important goals at the same time - restoration of hearing and safety, since they are surgical positioned beneath or through the skin. BONEBRIDGE fulfils simultaneously the following aspects:

- biocompatible with human tissues (it is surgical positioned in the bone behind the ear)

- $\quad$ fixation with biocompatible screws

- $\quad$ low biofilm formation

The BONEBRIDGE is a semi-implantable system, consisting of an implantable part (bone conduction implant-BCI 601) and the externally worn audio processor (SAMBA).

The materials in the Bonebridge were selected to be inert with respect to body tissue.

For the implanted parts, commonly used longterm implant materials were used. The materials in direct tissue contact are:

- Medical grade silicone elastomeres (types MED4750 and MED2-4213)

- $\quad \mathrm{Ti} 6 \mathrm{Al} 4 \mathrm{~V}$ according to ASTM F136

- Ti $6 \mathrm{Al} 7 \mathrm{Nb}$ according to ASTM F1295 for the cortical screws

The BCI is the implantable part of the BONEBRIDGE device and consists of a magnet surrounded by the receiver coil, the electronics (demodulator), a bendable transition and the innovative, highly efficient Bone Conduction - Floating Mass Transducer (BC-FMT) (Figure 6). 


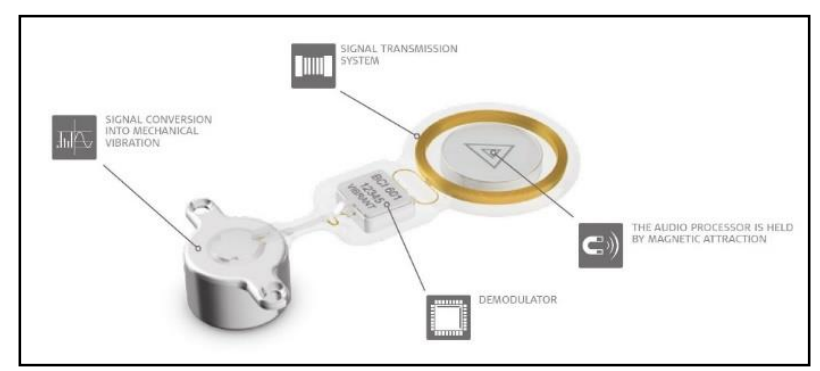

Figure 6. Bone conduction implant (BCI) from BONEBRIDGE (with MEDEL Company courtesy)

BONEBRIDGE stimulator is implanted completely under the skin. Due to high probability that patient might need an MRI evaluation at least once in a life-time, it was extensively tested for this condition. Patients with BONEBRIDGE can perform MRI under 1.5 Tesla without need of extraction because the BCI can be tested safely in static magnetic field of 1.5 Tesla or less, with spatial gradient field of $118 \mathrm{~T} / \mathrm{m}$ or less, spatial gradient field product of $141 \mathrm{~T} 2 / \mathrm{m}$ or less and with maximum whole body averaged (WBA) specific absorption rate (SAR) of $<2.3 \mathrm{~W} / \mathrm{kg}$ at 1.5 Tesla, for 15 minutes of continuous MR scanning.

In non-clinical testing the BONEBRIDGE produced a temperature rise of $2.0^{\circ} \mathrm{C}$ (with a background temperature increase of $\approx 1.6^{\circ} \mathrm{C}$ ) at a maximum whole body averaged specific absorption rate (SAR) of $\approx 2.3 \mathrm{~W} / \mathrm{kg}$ assessed by calorimetry for 15 mins. of continuous MR scanning with body coil in a 1.5 Tesla Intera, Philips Medical System (PMS) (Software: Release 12.6.1.3, 2010-12-02) MR Scanner.

MR image quality is compromised of course in the area of its location, with worst-case image artifacts expected to affect the image in a surrounding area with a radius of 15 $\mathrm{cm}$ measured from the geometrical center of the implant.

The BCI is fixated in the mastoid bone by Titanium screws, which ensure a direct bone conduction of the acoustic energy (Figure 7), transmitted from the sound processor directly to the BCI. This direct mechanical connection offers many benefits, for example higher output for mixed hearing loss and single-sided deafness. Due to the intact skin technique, BONEBRIDGE offers stable output, independent of skin thickness or hair growth and no skin pressure necessary for stimulation.

If there is insufficient depth of the mastoid bone for fixation, BCI lifts are use. For the BCI Lifts, the materials which come into contact with body tissue are:

- OXPEKK-IG200;

- Cortical screws: Ti $6 \mathrm{Al} 7 \mathrm{Nb}$ according to ASTM F1295.

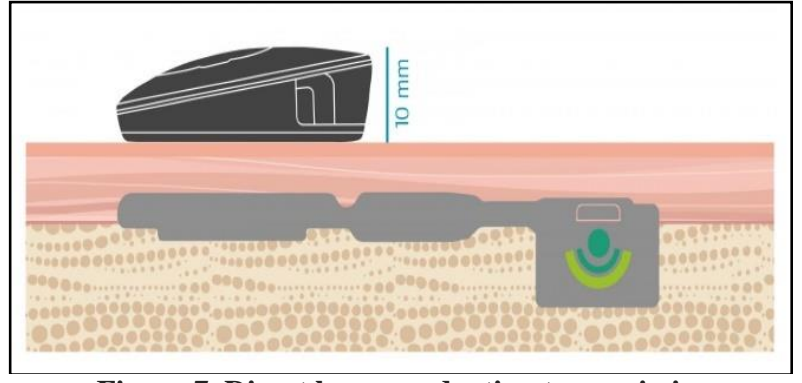

Figure 7. Direct bone conduction transmission

The coil receives transcutaneously electronic signals from the audio processor and convents them into mechanical sound vibrations of the BC-FMT. These vibrations are directly conducted through the bone to the cochlea, where they are processed like normal sound and have the effect of a natural sound quality [6-9].

External part of the BONEBRIDGE is represented by a sound processor, the low-profile SAMBA Audio Processor. It detects sounds and sends the signals to the implant coil through radiofrequency transmission. The sound processor (Figure 8) fixates very easy on the internal magnet of the BCI through its own magnet and ensures a good coupling of the two magnets, with very good transmission of the incoming signals.

For the Samba, the materials in direct body contact are:

- Eastman Tritan Copolyester MX731 (Color formulated for anthracite RAL 7016);

- $\quad$ Printcolor Series 752 ink; type 9005 (white).

Biological safety of all materials used in BONEBRIDGE system, internal and external part, was preclinically established according to ISO 10993.

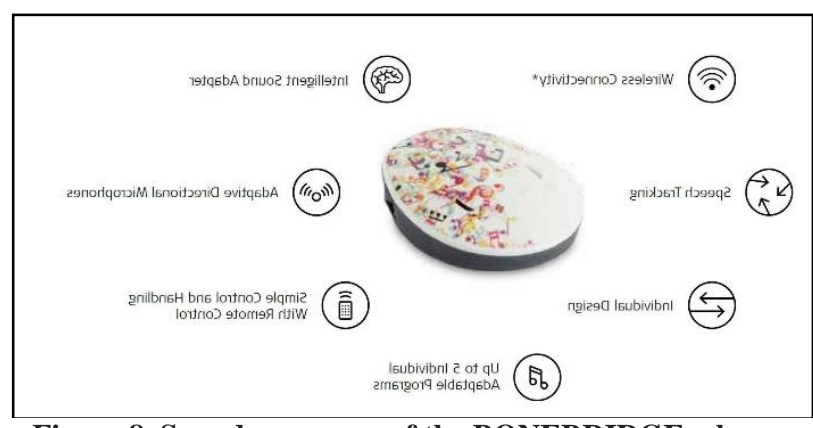

Figure 8. Sound processor of the BONEBRIDGE - large connectivity possibilities

The adaptive directional microphones automatically detect and minimize background noise. This feature is particularly useful in situations where the noise can be louder, for example, in a restaurant. With the SAMBA, users can effortlessly take part in conversations with background noise from behind or to the side being automatically omitted.

The SAMBA offers wireless connectivity via Bluetooth or telecoil and plugs into external devices. 
Through this new feature users can connect to their mobile phones, MP3 players, FM systems or other wireless devices without losing any quality of sound. This new function is possible by using an interface, the Siemens miniTek $^{\mathrm{TM}}[10-12]$.

\section{CONCLUSION}

BONEBRIDGE is a cosmetically appealing solution. The implant is completely invisible under the skin and the audio processor can be discretely worn under the hair. The covers of the new SAMBA audio processor can be interchanged. Users can choose a cover colour which discreetly matches the hair or one of the new designs, to make an expressive individual statement.

So, as you can see, BONEBRIDGE combines the best of both worlds in bone conduction:

- Active bone conduction for powerful amplification;

- Completely under-the-skin implant.

\section{REFERENCES}

[1] WHO report, May 2017.

[2] Tisch M. [Implantable Hearing Devices]. Laryngorhinootologie. (2017) Apr; 96(S01): S84S102.

[3] Bravo-Torres, S.; Der-Mussa, C.; Fuentes-Lopez, E. "Active transcutaneous bone conduction implant: audiological results in paediatric patients with bilateral microtia associated with external auditory canal atresia." International journal of audiology, 18, 2017.

[4] Zhao, SQ, Ren, R, Han, DM, Li, Y, Ma, XB, Wang, DN, Li, YL. (2017) “The implantation of Bonebridge in bilateral congenital malformation of external and middle ear." Zhonghua ErBi Yan Hou Tou Jing Wai Ke Za Zhi,. 52(7): p. 512-516.

[5] Sprinzl GM., Wolf-Magele A. (2016). "The Bonebridge Bone Conduction Hearing Implant: Indication criteria, surgery and a systematic review of the literature." Clin Otolaryngol. 41(2):131-43. doi: 10.1111/coa.12484.

[6] Gavilan J, Adunka O, Agrawal S, Atlas M, Baumgartner WD, Brill S, Bruce I, Buchman C, Caversaccio M, De Bodt MT, Dillon M, Godey B, Green K, Gstoettner W, Hagen R, Hagr A, Han D, Kameswaran M, Karltorp E, Kompis M, Kuzovkov V, Lassaletta L, Li Y, Lorens A, Martin J, Manoj M, Mertens G, Mlynski R, Mueller J, O'Driscoll M, Parnes L, Pulibalathingal S, Radeloff A, Raine $\mathrm{CH}$, Rajan G, Rajeswaran R, Schmutzhard J, Skarzynski H, Skarzynski P, Sprinzl G, Staecker H, Stephan K, Sugarova S, Tavora, Usami S, Yanov Y, Zernotti M, Zorowka P, de Heyning PV. "Quality standards for bone conduction implants." Acta OtoLaryngologica.135 (12); 1277-1285, 2015.

[7] Georgescu M., Vrinceanu D., Radulescu L., Tusaliu M., Martu C., Curutiu C., Hussien MD., Budu V. "Microbial biofilms and implantable hearing aids."
Romanian Biotechnological Letters Vol. 22, No. 4, 12681-12686, 2017, ISSN 1224-5984.

[8] Pirlich M, Dietz A, Meuret S, Hofer M.(2017) "Implantable Bone Conduction and Active Middle Ear Devices." Laryngorhinootologie. Feb; 96(2): 120-129.

[9] Volkenstein S., Thomas J.P., Dazert S. (2016) "Bone Conduction and Active Middle Ear Implants." Laryngorhinootologie. 95(5):352-63. doi: 10.1055/s0042-104946.

[10] Bianchin G., Bonali M., Russo M. \& Tribi L. "Active bone conduction system: outcomes with the Bonebridge transcutaneous device." ORL J Otorhinolaryngol Relat Spec, 77(1), 17-26,2015. doi: 10.1159/000371425.

[11] Tsang W. S., Yu J. K., Bhatia K. S., Wong T. K. \& Tong M. C. "The Bonebridge semiimplantable bone conduction hearing device: experience in an Asian patient.” J Laryngol Otol, 127(12), 1214-1221, 2013. doi: 10.1017/s0022215113002144.

[12] Sprinzl G., Lenarz T., Ernst A., Hagen R., WolfMagele A., Mojallal H., Wolframm M. D. "First European multicenter results with a new transcutaneous bone conduction hearing implant system: short-term safety and efficacy." Otol Neurotol, 34(6), 1076-1083, 2013. doi: 10.1097/MAO.0b013e31828bb541. 